\title{
Evaluation of Two Disease Warning Systems for Botryosphaeria Panicle and Shoot Blight of California Pistachio and Efficient Control Based on Early-Season Sprays
}

\author{
David P. Morgan, George F. Driever, and Dan Felts, University of California, Department of Plant Pathology, Uni- \\ versity of California, Davis, Kearney Agricultural Center, Parlier 93648; William H. Krueger, University of Cali- \\ fornia, Cooperative Extension, Orland 95963; and Themis J. Michailides, University of California, Department of \\ Plant Pathology, Davis, Kearney Agricultural Center
}

\begin{abstract}
Morgan, D. P., Driever, G. F., Felts, D., Krueger, W. H., and Michailides, T. J. 2009. Evaluation of two disease warning systems for Botryosphaeria panicle and shoot blight of California pistachio and efficient control based on early-season sprays. Plant Dis. 93:1175-1181.

Two empirical models to predict infection events were evaluated for control of Botryosphaeria panicle and shoot blight, caused by a Fusicoccum sp., as well as the effectiveness of early-season fungicide sprays on the control of this disease of pistachio. A model incorporating wetness duration was superior to one based solely on duration of rains $\geq 1 \mathrm{~mm} / \mathrm{h}$ for $\geq 4 \mathrm{~h}$ and with temperature $\geq 11^{\circ} \mathrm{C}$. The wetness duration threshold $(W)$ for rain events $\geq 4 \mathrm{~mm}$ at a given temperature ( $T$ ) for high-risk infection events was $W=-7.8+397 / T$ and the threshold for medium-risk events was $W=-6.9+220 / T$. Wet periods interrupted by $\leq 12 \mathrm{~h}$ were added together to calculate $W$. In two orchards with high levels of inoculum, one high-risk event resulted in 20 to $23 \%$ blighted fruit at harvest and two or three high-risk events resulted in 31 to $80 \%$ blighted fruit. Latent infections were 0 to $1 \%$ in instances where only low-risk events (one to two events) occurred prior to collection of pistachio fruit for determination of latent infections and were 17 to $36 \%$ with one to three high-risk events. Early-season fungicide sprays in April to May effectively controlled panicle and shoot blight when applied up to 12 days before predicted infection events or 5 days after.
\end{abstract}

Panicle and shoot blight, caused by a Fusicoccum sp. anamorph of Botryosphaeria dothidea (Moug.:Fr.) Ces. \& De Not., is an important disease of pistachio (Pistacia vera L.) in California. Although the disease was first observed in 1984 in only a few orchards in the northern Sacramento Valley, by the 1990s it was spreading south, with only orchards in the southern and western portions of the San Joaquin Valley free from the disease (12). In 1998, a combination of a warm and very wet spring and the lack of effective registered fungicides resulted in an epidemic with high levels of this disease in many orchards (12). Previous research has shown

Corresponding author: T. J. Michailides

E-mail: themis@uckac.edu

* The $e$-Xtra logo stands for "electronic extra" and indicates that a supplemental figure is available online.

Present address of G. F. Driever: Oklahoma State University, Cooperative Extension Pest Management Specialist, Muskogee, OK 74401.

Present address of D. Felts: University of California, Department of Plant Pathology, University of California, Riverside, Kearney Agricultural Center, 9240 South Riverbend Ave., Parlier 93648.

Accepted for publication 13 July 2009.

doi:10.1094/PDIS-93-11-1175

(C) 2009 The American Phytopathological Society that, in California pistachio orchards, the Fusicoccum sp. is entirely splash dispersed (2). Infections which occur during earlyseason spring rains can remain latent until later in the growing season (19). A positive relationship between latent infections and disease severity has been observed which may be useful to predict disease incidence $(1,16)$. Although it is unclear what factors trigger the development of latent infections into lesions, the pathogen grows best at relatively high temperatures (11), and symptoms can become severe as temperatures rise in late spring or summer (1). The importance of rain, wetness period, and temperature on disease development have been described previously (11), and models have been developed to predict epidemics $(16,17)$, but no decision support system has been developed to advise growers when to spray. In the absence of such a system, growers currently apply as many as seven fungicide sprays to control this disease (K. Kaplan, pistachio grower, Chico, CA, personal communication).

An empirical infection model based on field observations was developed to predict when weather conditions are favorable for infection by the Fusicoccum sp. The Botryosphaeria infection model (BIM) (4) is based on previous studies $(5,11)$ and was developed to determine whether infection events could be predicted using data from California Irrigation Management Information System (CIMIS) weather stations, which do not have electronic wetness sensors. The model predicts that infection events by the Fusicoccum sp. occur in orchards where the pathogen has been established when temperature is $\geq 11^{\circ} \mathrm{C}$ and rain $\geq 1 \mathrm{~mm} / \mathrm{h}$ for $\geq 4 \mathrm{~h}$. In addition, we report the development and initial evaluation of a second empirical infection model called the leaf wetness model (LWM), also based on previous studies $(4,11)$ This model was developed because it became apparent that the BIM, while simple and easily monitored by growers, might be limited in effectiveness if the variations in length of infection period at different temperatures were ignored. Furthermore, relative humidity is generally quite low during the day in California and rains ending after daybreak generally dry out quite rapidly; however, leaves often remain wet until morning if rainstorms end after sunset. The LWM attempts to correct these potential flaws with the BIM. The objectives of this study were to (i) determine whether the disease can be efficiently controlled by spraying close to the time of occurrence of early-season rain events, especially those that exceed the threshold conditions for these infection models; (ii) validate the BIM and LWM models; and (iii) quantify relationships between latent infections and disease incidence.

\section{MATERIALS AND METHODS}

Orchard disease risk assessments. Commercial pistachio orchards used in this study included one in Glenn County in the Sacramento Valley, one in San Joaquin County in the northern San Joaquin Valley, and one each in Madera and Tulare Counties in the Central San Joaquin Valley. All orchards were planted to cv. Kerman, which is highly susceptible to the Fusicoccum sp. In order to estimate primary inoculum, 150 rachises retained on the tree from earlier years were collected in each orchard in March 2004 and March 2005 and examined after sectioning for the presence of pycnidia of the Fusicoccum sp. Rachises were sampled because these represent the most abundant source of primary spore inoculum (14) and can provide inoculum for at least 6 years (15). The Glenn County orchard was planted in 1978 and had drip irrigation. The San Joaquin County orchard was planted in 1981 and was irrigated with low-angle solid-set 
sprinklers which did not wet the canopy. The Madera County orchard was planted in 1971 and was irrigated with fanjet microsprinklers. The Tulare County orchard was planted in 1983 and had a dripirrigation system.

Latent infections. Latent infections were determined by the overnight freezing and incubation technique (ONFIT) (13) with a modified sterilization protocol (16). Briefly, fruit were sterilized in $70 \%$ ethanol for 10 to $15 \mathrm{~s}$ and then in $0.525 \%$ sodium hypochlorite with $0.05 \%$ Tween 20 for $4 \mathrm{~min}$. The fruit were placed in plastic containers on plastic screens. After adding water to cover the bottom, the containers were frozen at $-16^{\circ} \mathrm{C}$ for 16 to $20 \mathrm{~h}$ and then incubated at $28^{\circ} \mathrm{C}$ for 7 days. For fungicide experiments, 50 fruit were sampled from each of five replicate trees. For other studies, five samples of 50 fruit each were collected from unsprayed trees in each orchard, except in Glenn County from 1999 to 2001 and San Joaquin County from 1999 to 2000, when 50 fruit per orchard were collected. Fruit were collected near the end of the rainy season because no significant changes in number of latent infections using ONFIT occurred from samples collected after early June (16). In most years, collections were made near 20 May; however, collection dates ranged from 13 May to 21 June.

Disease incidence. Disease incidence was determined at harvest by recording 200 fruit from each of five replicate trees per orchard. Blighted fruit included infected fruit, which are black or silver-gray and covered with pycnidia, and light tan fruit, which are killed as a result of girdling of a portion of the rachis infected by the fungus. The only exception was the Glenn County orchard in 1998, where disease incidence was estimated based on yield losses determined from grower esti-

Table 1. Primary inoculum potential of panicle and shoot blight disease in pistachio orchards used in study

\begin{tabular}{lcc}
\hline Orchard & $\begin{array}{c}\text { Retained } \\
\text { rachises with } \\
\text { pycnidia of } \\
\text { Fusicoccum } \text { sp. } \\
(\%)^{\mathbf{z}}\end{array}$ & $\begin{array}{c}\text { Classification } \\
\text { of primary } \\
\text { inoculum }\end{array}$ \\
\hline Glenn & $54 \mathrm{a}$ & High \\
San Joaquin & $56 \mathrm{a}$ & High \\
Madera & $23 \mathrm{ab}$ & Medium \\
Tulare & $5 \mathrm{~b}$ & Low \\
\hline
\end{tabular}

${ }^{\mathrm{z}}$ Average of 2004 and 2005 years. Numbers followed by different letters are significantly different according to a least significant difference test $(P<0.05)$. Statistical analysis was performed on arcsine-transformed data. Values presented were back transformed from the means for the arcsine-transformed data. Because these rachises can be retained on the trees for years, analysis of variance was performed using the different years as replications. mates and grower receipt statements from the processing plant.

Fungicide experiments. Fungicide trials were conducted in 2002 (moderate disease incidence), 2004 (low incidence), and 2005 (high incidence) in a commercial pistachio orchard in Glenn County. Experimental treatments were applied either before or after rain events. For spraying before rain events, the National Oceanic and Atmospheric Administration weather forecast was monitored closely and fungicides were applied when there was $>80 \%$ probability of rain. Fourteen days after a fungicide application, fungicides were applied for additional rain events. In addition, in some years, fungicide applications were applied after rain events, after model thresholds were actually exceeded. Fungicides were applied with a handgun sprayer at 935 liters/ha near bloom and 3,738 liters/ha for applications other than during bloom. Thiophanate-methyl was applied at bloom and azoxystrobin or a mixture of pyraclostrobin and boscalid (Pristine) were applied later in the season. The grower applied fungicides with an air-blast sprayer at 935 liters/ha operated at 6.9 bars. Hemipteran insects, which can also spread conidia of the Fusicoccum sp. (12), were controlled with insecticides included in the grower's fungicide sprays but not with the experimental sprays. Treatments consisted of five singletree replications using a randomized complete block design. Samples from five arbitrarily selected trees in the adjacent section treated by the grower were evaluated at harvest. In total, 100 panicles/tree were recorded to determine the incidence of blighted panicles. Disease incidence was also determined on 200 fruit, 30 rachises, and 50 leaves per replicate tree.

LWM. Three-year-old cv. Kerman trees in 30-cm-diameter pots were placed in a growth chamber (Model GC36; Environmental Growth Chambers, Chagrin Falls, $\mathrm{OH})$ at $10,20,30$, and $35^{\circ} \mathrm{C}$ in separate experiments and allowed to adjust to the temperatures overnight. Trees were inoculated with the Fusicoccum sp. at $5 \times 10^{4}$ pycnidiospores $/ \mathrm{ml}$ in aqueous suspensions applied with a hand sprayer to runoff. Each tree was misted with approximately $50 \mathrm{ml}$ of inoculum suspension. The chamber was equipped with a misting system that provided water vapor saturation and was calibrated to provide humidity levels of $98 \%$. At each temperature, three trees were exposed to periods of $0,4,8,12$, or $24 \mathrm{~h}$ of wetness duration. Trees were allowed to air dry at ambient daytime temperatures before they were moved outside with full sunlight ( 24 to $27^{\circ} \mathrm{C}$ average). The control trees ( $0 \mathrm{~h}$ of wetness) were removed from the growth chamber prior to inoculation and inoculated in the holding area adjacent to the growth chamber. Growth chamber experiments were conducted three times. Disease severity on the leaves was recorded using the Horsfall-Barratt rating scale (7) but regressions were performed when data were converted to percentage of leaves with lesions. These trees did not have any panicles. Disease incidence was determined 21 days after inoculation. Although the same trend was observed for each experiment, regression analysis was performed on the third trial because no rains occurred after these trees were removed from the growth chamber and were exposed to ambient conditions prior to disease recording. For each temperature, regression was performed using the equation $I=a\left(1-e^{-b W}\right)$, where $I=$ percentage of leaves with lesions of the Fusicoccum sp. and $W=$ wetness duration. Then, the relationship between temperature and leaf wetness periods resulting in 5 and $10 \%$ leaves with lesions was determined using the equation $W=a+b / T$, where $T=$ temperature.

To determine the relationship between wetness periods and temperature in the field, only disease and weather data from the Glenn and San Joaquin orchards were used because they had similar high levels of primary inoculum (Table 1). Wetness periods initiated by rain with $\geq 4 \mathrm{~mm}$ of rain per event were included. Because it was previously determined that spores subject to at least $12 \mathrm{~h}$ of drying can resume germination and infection when rewetted (11), wetness periods separated by $\leq 12 \mathrm{~h}$ were combined with preceding wetness periods. In order to determine the threshold between medium- and high-risk predicted infection events, all rain events $\geq 4 \mathrm{~mm}$ regardless of the length of wetness period from years with high disease incidence (31 to $80 \%$ blighted fruit) were used. In order to determine the threshold between low- and medium-risk predicted infection events, rain events with similar parameters from years with low disease incidence ( 0 to $3 \%$ blighted fruit) were used. The nonlinear regression was performed by using the equation $W=a+b / T$, where $W=$ wetness duration and $T=$ temperature.

Weather recording. Predicted infection events for the BIM (4) were calculated using the closest CIMIS weather station. The closest CIMIS station was $11 \mathrm{~km}$ from the Glenn County orchard (except in 2005 when, due to a faulty rain sensor, we had to use data from a station which was 48 $\mathrm{km}$ away), $21 \mathrm{~km}$ from the San Joaquin orchard, $16 \mathrm{~km}$ from the Madera orchard, and $23 \mathrm{~km}$ from the Tulare orchard. In addition, predicted infection events for the BIM and the LWM were also calculated from orchard-based weather stations (Models CR10X, 21X, or CR23X; Campbell Scientific, Inc., Logan, UT) equipped with temperature and relative humidity sensors (Model HMP45; Vaisala Inc., Vantaa, Finland), painted (6) electronic wetness sensors (Model 237; Campbell Scientific, Inc.) deployed in the middle of the canopy at a $45^{\circ}$ angle facing north (8), and 
a tipping bucket rain gage (Model TE525WS; Texas Electronics, Dallas). Predicted infection events for these two models are presented in Table 2.

Data analysis. Analysis of variance was used and means were separated by the least significant differences at $P<0.05$. Percentage data were arcsine transformed $(9,10)$, except for regressions of wetness periods versus temperature (Figs. 1 and 2). All analyses except for nonlinear regression were done using SAS (version 9.1; SAS Institute, Inc., Cary, NC). SigmaPlot (version 10; Systat Software, Inc., San Jose, $\mathrm{CA}$ ) was used for nonlinear regressions.

\section{RESULTS}

Orchard inoculum levels. The orchards in Glenn and San Joaquin Counties had high levels of primary inoculum: about $55 \%$ of the rachises had pycnidia of Fusicoccum sp. (Table 1). The orchard in Madera County, where $28 \%$ of rachises bore pycnidia of Fusicoccum sp., had a medium level of primary inoculum. The orchard in Tulare County, where $5 \%$ of rachises had pycnidia of Fusicoccum sp., was categorized as having a low level of primary inoculum.

Latent infections and disease incidence. There was a highly significant relationship $(P<0.0001)$ between incidence of latent infection determined after the rainy season and disease incidence at harvest, expressed by linear regression as $y=0.09$ $+0.71 x(R=0.93)$, where $y=\operatorname{arcsine}-$ transformed blighted fruit at harvest and $x$ $=$ arcsine-transformed latent infections. Years where high-risk or medium-risk predicted infection events occurred after the sampling date were excluded from the regression, although the relationship was still highly significant with those years' data included $(P<0.0001, R=0.87)$. Incidence of latent infection during 1999 to 2004 varied from 0 to $92 \%$ (Table 2). Low incidence $(\leq 1 \%)$ resulted in 0 to $10 \%$ blighted fruit at harvest. In 3 of the 4 years when latent infections were $\leq 1 \%$, blighted fruit was 0 to $3 \%$. In the fourth year, in Glenn County in 1999, 0\% latent infections resulted in $10 \%$ blighted fruit but a medium-risk predicted infection event according to the LWM occurred on 2 June after the ONFIT had been determined (Table 2). Moderate levels of latent infections (between 6 and 21\%) resulted in a range of 7 to $31 \%$ blighted fruit at harvest. High levels of latent infections ( $>30 \%)$ resulted in 51 to $62 \%$ blighted fruit. Latent infections were not determined during the epidemic year of 1998 .

Evaluation of the LWM and BIM. The $R$ values for the growth chamber experiments for the initial regression of the relationship between leaves with lesions and wetness duration for the equation $I=a(1-$ $e^{-b W}$ ) were $0.87,0.78,0.77$, and 0.36 for $10,20,30$, and $35^{\circ} \mathrm{C}$, respectively. Equations and $R$ values for the relationship between wetness duration and temperature at those four temperatures are shown in Figure 1. The regressions of the wetness periods calculated from the electronic wetness sensors associated with rain events $\geq 4 \mathrm{~mm}$ determined in the orchard in years with high disease incidence and low disease incidence are presented in Figure 2.

Examination of predicted infection events that occurred before the date the fruit were collected for ONFIT assays showed that latent infections were $\leq 1 \%$ when only low-risk infection events (zero to two) occurred according to the LWM (Madera 2004 and Glenn 1999, 2004, and 2008; Table 2). Latent infections were 0 to $14 \%$ when the category of predicted infection event according to the LWM was medium (Glenn 2001; San Joaquin 1999, 2001, and 2002; and Madera 2003). Latent infections were 17 to $36 \%$ when the category of predicted infection event according to the LWM was high (Glenn in 2000 , 2002, and 2003 and San Joaquin in 2000). Using the same orchard-based weather stations to determine BIM thresholds, 0 to $8 \%$ latent infections occurred when the BIM predicted no infection events (Glenn 1999, 2001, 2004, 2008 and San Joaquin 1999, 2001, and 2002). Latent infections were 14 to $36 \%$ in years when $\geq 1$ predicted infection event occurred according to the BIM (Glenn 2000, 2002, and 2003; Madera 2003; and San Joaquin 2000; Table 2).

The years with low incidence of blighted fruit (0 to 3\%) (Glenn in 2004, San Joaquin in 2001 and 2002, and Madera in 2004) were characterized by absence of high-risk infection events according to the LWM, zero to one medium-risk infection events, and zero to two low-risk infection events. The BIM, calculated using orchard data, also showed no predicted infection events during these years with low disease incidence, though the BIM using CIMIS data did predict an infection event in San Joaquin in 2001 (Table 2).

Years with moderate incidence of blighted fruit (7 to 23\%) (Glenn in 1999,

Table 2. Latent infections of Fusicoccum sp. and incidence of panicle and shoot blight of pistachio with predicted infection events based on California Irrigation Management Information System (CIMIS) and orchard-based (Orchard) weather data

\begin{tabular}{|c|c|c|c|c|c|c|c|c|}
\hline \multirow[b]{2}{*}{ Orchard } & \multirow[b]{2}{*}{ Year } & \multirow[b]{2}{*}{ Latent $(\%)^{\mathrm{y}}$} & \multirow[b]{2}{*}{ Blighted $(\%)^{\mathrm{z}}$} & \multicolumn{2}{|c|}{ Botryosphaeria infection model ${ }^{v, w}$} & \multicolumn{3}{|c|}{ Leaf wetness model ${ }^{v, x}$} \\
\hline & & & & CIMIS & Orchard & High risk & Medium risk & Low risk \\
\hline Glenn & 1998 & ND & 80 & $4(2,5 / 28,6 / 10)$ & $4(2,5 / 28,6 / 10)$ & $2(1,5 / 28)$ & $4(1,6 / 10)$ & 0 \\
\hline Glenn & 1999 & $0(5 / 13)$ & 10 & 0 & 0 & 0 & $1(1-6 / 2)$ & 1 \\
\hline Glenn & 2000 & $36(5 / 24)$ & 62 & 2 & 3 & 3 & $2(1-6 / 9)$ & 0 \\
\hline Glenn & 2001 & $8(5 / 16)$ & 23 & 0 & $1(1,6 / 27)$ & $1(1-6 / 27)$ & 1 & 0 \\
\hline Glenn & 2002 & $21(5 / 21)$ & 20 & 1 & 1 & 1 & 0 & 0 \\
\hline Glenn & 2003 & $17(5 / 17)$ & 31 & $1(1,8 / 2)$ & $2(1,8 / 2)$ & $3(1,8 / 2)$ & $1(1-8 / 22)$ & 3 \\
\hline Glenn & 2004 & $1(6 / 8)$ & 2 & 0 & 0 & 0 & 0 & 2 \\
\hline Glenn & 2005 & $92(5 / 25)$ & 60 & $3(1,7 / 16)$ & ND & ND & ND & ND \\
\hline Glenn & 2008 & $0(6 / 3)$ & 1 & 0 & 0 & 0 & 0 & 0 \\
\hline San Joaquin & 1999 & $6(5 / 16)$ & 12 & 0 & 0 & 0 & 1 & 3 \\
\hline San Joaquin & 2000 & $36(5 / 24)$ & 51 & 1 & 1 & 2 & 0 & 0 \\
\hline San Joaquin & 2001 & $0(5 / 16)$ & 3 & 1 & 0 & 0 & 1 & 1 \\
\hline San Joaquin & 2002 & $0(5 / 20)$ & 0 & 0 & 0 & 0 & 1 & $2(1)$ \\
\hline Madera & 2003 & $14(6 / 21)$ & 7 & 0 & 2 & 0 & 4 & 0 \\
\hline Madera & 2004 & $1(5 / 28)$ & 0 & 0 & 0 & 0 & 0 & 0 \\
\hline Tulare & 2003 & $9(5 / 13)$ & 10 & 0 & ND & ND & ND & ND \\
\hline Tulare & 2004 & $0(5 / 21)$ & 0 & 0 & ND & ND & ND & ND \\
\hline
\end{tabular}

$\mathrm{v}$ Numbers in parentheses indicate number and date of infection events that occurred after the fruit was collected for overnight freezing and incubation technique (ONFIT) or after average date for ONFIT collection for 1998. ND = not determined.

${ }^{\mathrm{w}}$ Predicted infection events for orchard-based stations and CIMIS stations; the latter were $11 \mathrm{~km}$ from Glenn, $21 \mathrm{~km}$ from San Joaquin, $16 \mathrm{~km}$ from Madera, and $23 \mathrm{~km}$ from Tulare.

$x$ Number of predicted infection events ( $\geq 4 \mathrm{~mm}$ rain) in risk categories.

y Latent infections after the rainy season determined on 250 fruit from unsprayed pistachio trees, except in Glenn 1999 to 2001 and San Joaquin in 1999 to 2000, when 50 fruit were used. Numbers in parentheses indicate date that fruit was collected for ONFIT assay.

${ }^{\mathrm{z}}$ Includes fruit with pycnidia and blighted fruit (dry yellow/beige fruit on blighted rachises) recorded from five replicated samples of 200 fruit evaluated in the laboratory, except for 1998 when disease estimated on actual yield loss based on grower's best estimate and processing plant grower receipt statements. 
2001, and 2002; San Joaquin in 1999; Madera in 2003; and Tulare 2004; Table 2) were characterized by up to one high-risk infection event according to the LWM, one to five medium-risk infection events, and zero to five low-risk infection events. From the orchard-based weather data, in 3 of the 5 years, one or two predicted infection events above the BIM thresholds were recorded while zero predicted infection events were recorded in the other two in-

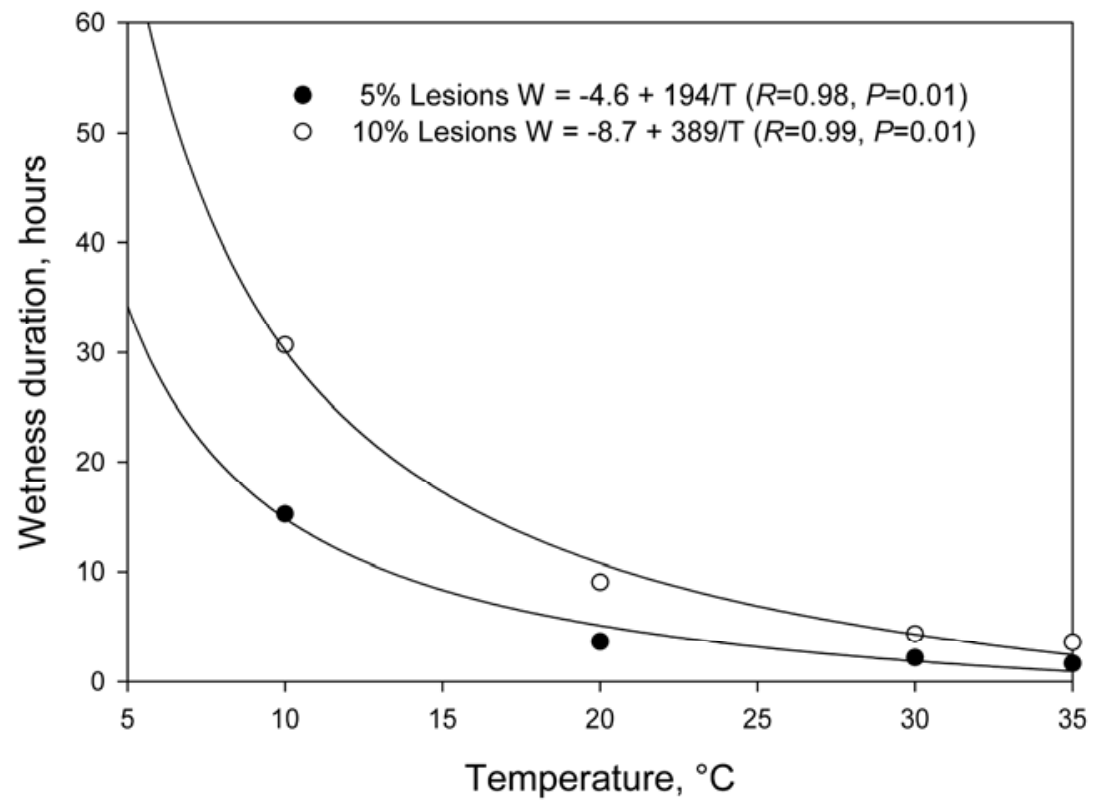

Fig. 1. Nonlinear regression of the relationship between wetness duration and temperature of potted pistachio trees inoculated with a Fusicoccum sp. in a growth chamber at 5 and $10 \%$ leaves with lesions.

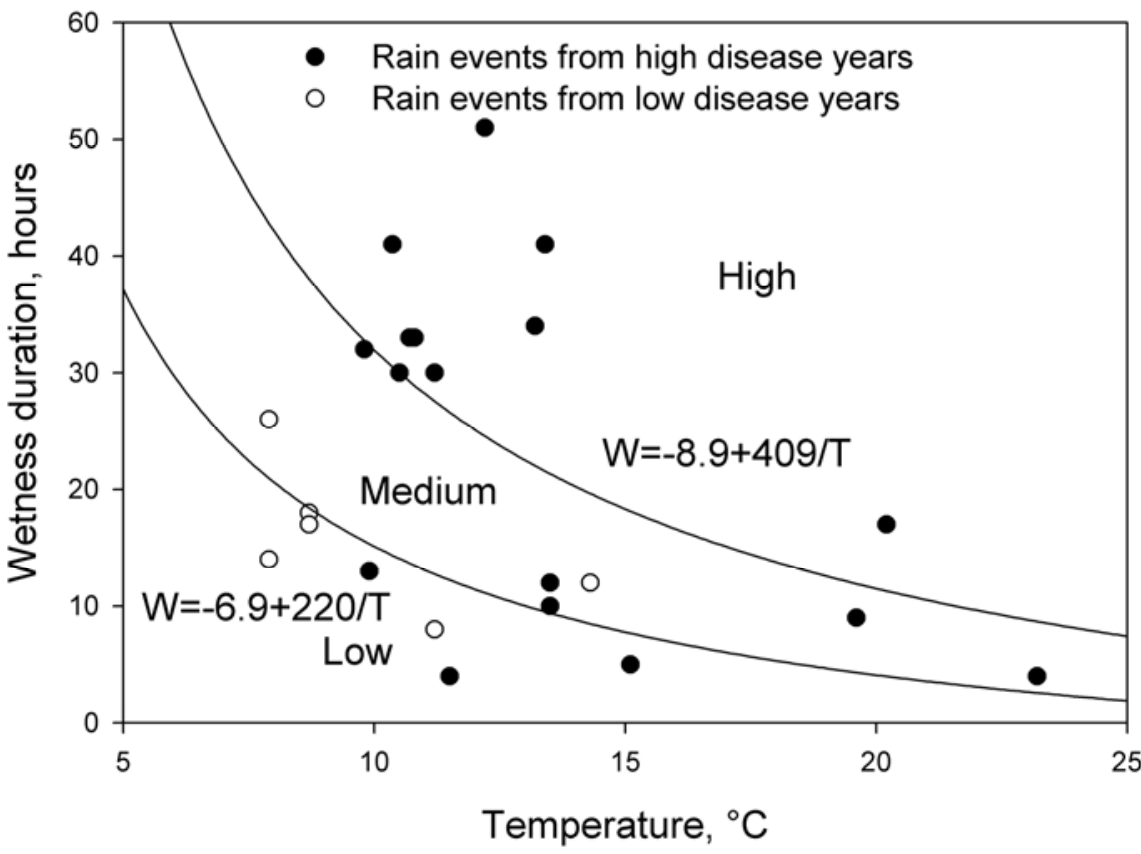

Fig. 2. Relative risk of infection of pistachio fruit by a Fusicoccum sp. by wetness period $(W)$ events and temperature $(T)$ combining wetness periods with $\leq 12 \mathrm{~h}$ of dry periods initiated by rain events with $\geq 4 \mathrm{~mm}$ of rain per event as recorded by electronic wetness sensors. $R$ value of medium-risk threshold equals $0.71(P=0.07)$ and of high-risk threshold equals $0.51(P=0.03)$. When determining wetness periods in orchard, wetness period had to be initiated with $\geq 4 \mathrm{~mm}$ of rain. Wetness periods interrupted by $\leq 12$-h dry period were added together, resulting in a single predicted infection event. events; and one to four predicted infection events according to the BIM using either orchard-based recorded weather or CIMIS data (Table 2).

Fungicide experiments; moderate disease pressure-2002. Latent infections on trees without fungicides increased from $0 \%$ on 7 May to $21 \%$ on 21 May (Table 3) compared with $1 \%$ for the trees sprayed with azoxystrobin on 7 May. The rain event that occurred on 19 May was categorized as a high-risk infection event according to the LWM and was also above the BIM threshold. Incidence of fruit with pycnidia was $1 \%$ with the grower's sprays and the single azoxystrobin spray on 7 May compared with $4 \%$ for the control (Table 3). Panicle blight on the trees at harvest was $5 \%$ for the azoxystrobin spray and $19 \%$ for the control (significantly different at $P<0.05$ ). Incidence of blighted fruit at harvest was 10 and $12 \%$ for the rain-based spray and the grower treatment schedule (total of 5 sprays), respectively, whereas the unsprayed control was $20 \%$ and not significant $(P<0.05)$.

Low disease pressure-2004. This season had no high- or medium-risk infection events according to the LWM and no predicted infection events according to the BIM (Table 2). Disease incidence was $2 \%$ in the unsprayed control, and none of the spray schedules resulted in any significant $(P<0.05)$ improvement (Table 4$)$.

High disease pressure-2005. BIM thresholds were exceeded on 8 May, 18 May, and 14 June according to off-site CIMIS data. No orchard-based weather station was available. Two sprays of Pristine on 22 April (sprayed before a predicted rain event that resulted in less than expected rainfall) and 3 May (which protected the pistachio trees from the first two of these predicted infection events) resulted in $4 \%$ blighted panicles on the tree and $8 \%$ blighted fruit (Table 5). The untreated control had $52 \%$ blighted panicles and $60 \%$ blighted fruit. The two sprays of Pristine resulted in significantly less disease than the unsprayed control $(P<0.05)$ and was in the same mean separation group as the grower's six sprays in blighted panicles and leaves with symptoms but not blighted fruit. One spray of Pristine was significantly better $(P<0.05)$ than the control but not in the same mean separation group as the grower's spray schedule.

\section{DISCUSSION}

This study, using data from more seasons than considered previously, validated results of previous studies suggesting that latent infections as determined by ONFIT could predict panicle and shoot blight incidence $(1,16)$ and that latent infections determined at the end of the rainy season are a good predictor of disease incidence at harvest (16). In general, when the incidence of latent infections was very low 
$(\leq 1 \%)$, panicle blight at harvest was also low. An exception occurred in Glenn County in 1999, when there was a medium-risk infection event after the ONFIT determination. Although the incidence of latent infections after the rainy season was a good predictor of disease incidence at harvest, in years where medium- or highrisk infection events according to the LWM occurred after samples for ONFIT were collected (Table 2), disease incidence at harvest was higher than predicted by the ONFIT.

There are several reasons why sprays for early-season rain events are particularly effective against panicle and shoot blight. First, average daily precipitation amounts in California peak in late winter and decline rapidly thereafter, and most of the remaining rain events occur before late May. Of the 28 medium- or high-risk infection events according to the LWM (Table 2), only 7 occurred after latent infections were determined and 5 of these occurred shortly thereafter, from 28 May to 27 June. The other two predicted infection events occurred on 2 and 22 August. Second, because they have more time to expand, it is likely that early infections resulted in more blighted fruit per cluster. Third, if panicles and leaves are infected early in the growing season, these lesions have more time to develop pycnidia which could provide additional inoculum for later rains to disperse. However, the infection results indicated that it is likely that medium- and high-risk infection events which followed the sampling date of latent infections contributed to disease development and needed to be sprayed with fungicides. When medium- or high-risk infection events occurred after the collection of fruit for ONFIT determination, final disease incidence was always higher than the regression equation predicted. Results of two seasons $(20,21)$ from weekly inoculations in the orchard of both wounded and nonwounded pistachio fruit showed that, although young fruit were somewhat more susceptible, fruit remained susceptible to infection through the final inoculation date in mid-August. Another study (18) with pistachio fruit collected from early June to late July and inoculated in humid chambers concluded that fruit seemed to be most susceptible when the kernel had almost reached its full size in late July. Thus, the effectiveness of early-season sprays seems to have more to do with the pattern of rain events than with differences in ontogenic fruit susceptibility. These studies on the susceptibility of pistachio fruit suggest that medium- or high-risk events should probably be treated, regardless of when they occur during the growing season.

One or two fungicide sprays early in the growing season generally provided control similar to 5 to 7 sprays by the grower (Tables 3 to 5), who often applied fungicides after low-risk infection events or rain events $<4 \mathrm{~mm}$. Because experimental trees in the fungicide treatments did not include insecticides to control Hemipteran insects, and these insects can transmit the disease (12), it is possible that disease control in the experimental trees would have been better

with the inclusion of these insecticides. These results suggest that none to a few well-timed fungicide applications can substitute for up to seven fungicide applications applied by some growers, and may be only necessary when rain events exceed LWM medium-risk and high-risk thresholds.

Table 3. Efficacy of fungicide sprays before rain events on panicle and shoot blight of pistachio in Glenn County $(2002)^{t}$

\begin{tabular}{|c|c|c|c|c|c|}
\hline \multirow[b]{2}{*}{ Treatment } & \multicolumn{2}{|c|}{ Latent infections $(\%)^{\mathrm{u}}$} & \multirow[b]{2}{*}{ Panicles $(\%)^{\mathrm{v}}$} & \multirow[b]{2}{*}{ Pycnidia $(\%)^{\mathrm{w}}$} & \multirow[b]{2}{*}{ Fruit $(\%)^{x}$} \\
\hline & May 7 & May 21 & & & \\
\hline Azoxystrobin ${ }^{y}$ & $0 \mathrm{a}$ & $1 \mathrm{a}$ & $5 \mathrm{a}$ & $1 \mathrm{a}$ & $10 \mathrm{a}$ \\
\hline Control & $0 \mathrm{a}$ & $21 \mathrm{~b}$ & $19 \mathrm{~b}$ & $4 \mathrm{~b}$ & $20 \mathrm{a}$ \\
\hline Grower $^{\mathrm{z}}$ & ND & ND & ND & $1 \mathrm{a}$ & $12 \mathrm{a}$ \\
\hline
\end{tabular}

${ }^{\mathrm{t}}$ Numbers followed by different letters within columns are significantly different according to a least significant difference test $(P<0.05)$. Statistical analysis was performed on arcsine-transformed data Values presented were back transformed from the means for the arcsine transformed data. ND $=$ not determined.

${ }^{\mathrm{u}}$ Latent infections in pistachio fruit. Averages of five replicated samples of 50 fruit that were processed by overnight freezing and incubation technique.

${ }^{v}$ Bighted fruit panicles on tree. Averages of five replicated samples of 100 panicles that were evaluated on the tree on 9 September 2002.

${ }^{\text {w}}$ Fruit with pycnidia; averages of five replicated samples of 200 fruit collected on 10 September 2002 and evaluated in the laboratory.

$\times$ Blighted fruit includes blighted fruit and those with pycnidia.

${ }^{y}$ Azoxystrobin was sprayed on 7 May at $0.23 \mathrm{~kg}$ a.i. $\mathrm{ha}^{-1}$.

z Grower's fungicide schedule; sprays applied on 6, 16, and 27 April; 18 May; and 3 August.

Table 4. Efficacy of fungicide sprays before rain events on panicle and shoot blight of pistachio in Glenn County (2004) $)^{\mathrm{u}}$

\begin{tabular}{llcc}
\hline $\begin{array}{l}\text { First spray } \\
\text { on March 25 }\end{array}$ & $\begin{array}{c}\text { Second spray on } \\
\text { April 12 }\end{array}$ & $\begin{array}{c}\text { Fruit with pycnidia } \\
(\boldsymbol{\%})^{\mathbf{v}}\end{array}$ & $\begin{array}{c}\text { Blighted fruit } \\
(\boldsymbol{\%})^{\mathbf{v}, w}\end{array}$ \\
\hline Thiophanate-methyl ${ }^{\mathrm{x}}$ & Pristine & $1.7 \mathrm{a}$ & $1.7 \mathrm{a}$ \\
$\ldots$ & Pristine & $0.7 \mathrm{a}$ & $1.0 \mathrm{a}$ \\
Untreated & Untreated & $1.9 \mathrm{a}$ & $2.3 \mathrm{a}$ \\
Grower $^{\mathrm{z}}$ & $\ldots$ & $1.2 \mathrm{a}$ & $4.8 \mathrm{~b}$ \\
\hline
\end{tabular}

" Numbers followed by different letters within columns are significantly different according to a least significant difference test $(P<0.05)$. Statistical analysis was performed on arcsine-transformed data. Values presented were back transformed from the means for the arcsine transformed data.

${ }^{v}$ Averages of five replications of 200 fruit each collected on 24 August 2004 and evaluated in the laboratory.

${ }^{\mathrm{w}}$ Includes fruit with pycnidia and blighted fruit (dry yellow or beige fruit on blighted rachises).

${ }^{x}$ Thiophanate-methyl was sprayed at $1.12 \mathrm{~kg}$ a.i. $\mathrm{ha}^{-1}$.

${ }^{y}$ Mixture of pyraclostrobin and boscalid was sprayed at 0.11 and $0.22 \mathrm{~kg} \mathrm{a}^{2}$.i. ha ${ }^{-1}$, respectively.

${ }^{\mathrm{z}}$ Grower's fungicide spray schedule consisted of thiophanate methyl at $1.12 \mathrm{~kg}$ a.i. ha $\mathrm{h}^{-1}$ on $20 \mathrm{March}$; azoxystrobin at $0.23 \mathrm{~kg}$ a.i. $\mathrm{ha}^{-1}$ on 9 April, 4 May, and $29 \mathrm{June}$; a mixture of pyraclostrobin and boscalid at 0.13 and $0.26 \mathrm{~kg}$ a.i. ha ${ }^{-1}$, respectively, on 18 May and 7 June; and pyraclostrobin on 21 July at $0.22 \mathrm{~kg}$ a.i. $\mathrm{ha}^{-1}$ (seven sprays in total).

Table 5. Efficacy of fungicide sprays before or after rain events on panicle and shoot blight of pistachio in Glenn County $(2005)^{\mathrm{u}}$

\begin{tabular}{lcccc}
\hline $\begin{array}{l}\text { Spray before second } \\
\text { rain (22 April) }\end{array}$ & $\begin{array}{c}\text { Spray after second } \\
\text { rain (3 May) }\end{array}$ & $\begin{array}{c}\text { Blighted fruit panicles } \\
\text { on tree }(\%)^{\mathbf{v}}\end{array}$ & $\begin{array}{c}\text { Blighted fruit } \\
(\%)^{\mathbf{w}}\end{array}$ & $\begin{array}{c}\text { Leaves with } \\
\text { lesions }(\%)^{\mathbf{x}}\end{array}$ \\
\hline Pristine & $\ldots$ & $13 \mathrm{~b}$ & $15 \mathrm{~b}$ & $14 \mathrm{~b}$ \\
Pristine & Pristine & $4 \mathrm{c}$ & $8 \mathrm{c}$ & $17 \mathrm{~b}$ \\
Untreated & Untreated & $52 \mathrm{a}$ & $60 \mathrm{a}$ & $67 \mathrm{a}$ \\
Grower $^{\mathrm{z}}$ & $\ldots$ & $1 \mathrm{c}$ & $3 \mathrm{~d}$ & $9 \mathrm{~b}$ \\
\hline
\end{tabular}

u Numbers followed by different letters within columns are significantly different according to a least significant difference test $(P<0.05)$. Statistical analysis was performed on arcsine-transformed data. Values presented were back transformed from the means for the arcsine transformed data.

${ }^{\mathrm{v}}$ Fruit panicles with the main rachis blighted from a sample size consisting of 100 panicles per five replicated trees.

${ }^{\mathrm{w}}$ Includes fruit with pycnidia and blighted fruit (dry yellow/beige fruit on blighted rachises) recorded from five replicated samples of 200 fruit evaluated in the laboratory.

${ }^{x}$ Averages of five replicated samples of 50 leaves evaluated in the laboratory.

${ }^{y}$ Mixture of pyraclostrobin and boscalid at 0.13 and $0.26 \mathrm{~kg}^{2}$.i. ha ${ }^{-1}$, respectively.

${ }^{\mathrm{z}}$ Grower's fungicide spray schedule consisted of thiophanate-methyl at $1.12 \mathrm{~kg}$ a.i. ha ${ }^{-1}$ on $26 \mathrm{March}$; azoxystrobin at $0.23 \mathrm{~kg}$ a.i. ha ${ }^{-1}$ on 6 April, 26 April, and 14 May; then a mixture of pyraclostrobin and boscalid at 0.11 and $0.21 \mathrm{~kg}$ a.i. ha ${ }^{-1}$, respectively, on 6 June and 26 July (six sprays in total). 
The LWM was good at predicting levels of latent infections and disease incidence at harvest. In general, seasons with low-, medium-, and high-risk infection events resulted in low, moderate, and high incidence of latent infections. The LWM also categorized predicted infection events in a manner that closely followed the pattern of blighted fruit (Table 2). In orchards with high initial inoculum potential based on infected retained rachises (Glenn and San Joaquin), two to three high-risk infection events occurred in each year that resulted in high incidence of blighted fruit whereas, in general, low disease years were associated with low- to medium-risk events. These results show that, in epidemic years such as 1998, infections most likely occur as a result of relatively few high-risk infection events.

The two equations delimiting low-, medium-, and high-risk infection events for the LWM (Fig. 2) were very similar to the equations showing the relationship between wetness duration and temperature from the growth chamber experiments (Fig. 1). A weakness of the equation of the threshold separating low- from mediumrisk infection events is the fact that the $P$ value was only $0.07 \%$, but the fact that a similar equation was developed from the growth chamber experiments strengthens this case. The regression equations shown in Figure 1 are not intended to predict disease incidence on leaves in the field. The high level of inoculum used to inoculate the trees may not correspond to field situations, and only four temperatures were tested. These data show that generally similar equations were generated from the growth chamber and field data. Furthermore, the equations from the growth chamber experiments (Fig. 1) and field data (Fig 2) were similar to those developed for apple fruit infection by $B$. obtusa (3), and the LWM was similarly more efficient in predicting low- or high-risk infection than medium-risk infection events. In addition, the medium- and highrisk values (temperature and wetness duration) for the LWM (Fig. 2) are very similar to previous studies of this disease, where no disease developed on inoculated pistachio leaves given 0 to $6 \mathrm{~h}$ of leaf wetness, whereas leaf wetness of 9 to $12 \mathrm{~h}$ or longer resulted in symptoms and increased disease severity (11). Both the BIM and LWM were based on a minimum threshold of $4 \mathrm{~mm}$ of rain. A previous study with this fungus estimated that $16 \mathrm{~mm}$ was needed for spore dispersal of the Fusicoccum sp. (2). However, this estimate is based on a single year's data and from only one of three locations studied and included winter rains which are generally colder, thus requiring more rain for spore dispersal.

The BIM threshold, determined either in the orchard or by CIMIS, was exceeded in all high-disease years, but the BIM threshold often was not exceeded in moderate- disease years (Table 2). Using CIMIS data to run the BIM was even more problematic. For instance, BIM thresholds were not exceeded using CIMIS station data closest to Glenn in 1999, 2001, and 2003; San Joaquin in 1999; and Madera and Tulare orchards in 2003, although the incidence of infected fruit ranged from 10 to $23 \%$. Because the Tulare orchard had a low level of primary inoculum as determined by recording the percentage of retained rachises with pycnidia, to have $10 \%$ blighted fruit means that BIM thresholds were likely exceeded in the orchard but were not recorded by CIMIS station no. 14 that was located $23 \mathrm{~km}$ away. It appears that, considering the variability in rain intensity, it is problematic to rely on CIMIS data only to predict infection events for the BIM, especially for events near the BIM threshold.

By categorizing rains $\geq 4 \mathrm{~mm}$ into three infection risk categories, growers and pest control advisors have a tool to manage this disease based on their knowledge of the disease history of the orchard, or their estimate of primary inoculum, or the amount of risk they can tolerate. A grower with very high inoculum might consider spraying for all medium- or high-risk infection events, and perhaps even low-risk events near the medium-risk threshold line, whereas a grower with moderate or low inoculum might consider spraying for only high-risk events or events considerably above the medium-risk threshold.

This study evaluated two empirical disease warning systems to help growers decide when to spray fungicides to control infections of the Fusicoccum sp. on pistachio. The results suggest that the LWM model is more accurate, especially with discerning low-risk from medium-risk events, but the BIM model is only effective at pinpointing infection events in highdisease years. The relationship between latent infections and panicle and shoot blight at harvest should provide growers with an additional tool to help them verify if infections took place. Although we used the percentage of retained rachises with pycnidia of the Fusicoccum sp. as a tool to estimate primary inoculum, this is a timeconsuming process, and other indices of primary inoculum, such as the presence of perennial cankers on branches, incidence of Fusicoccum sp. in buds (12), or the orchard history with this disease, are probably sufficient. Our results showing the effectiveness of early-season sprays illustrate the potential for reducing fungicide applications, especially if sprays are applied before or soon after rains above threshold conditions for infection as defined by these two models.

\section{ACKNOWLEDGMENTS}

We thank the California Pistachio Commission for financial assistance for this project and Pioneer Nursery for donating trees for the growth chamber experiments; M. T. Syvongxay, N. Enns, and H.
Reyes for technical assistance with this project; $\mathrm{K}$. Kaplan, R. Schrum, C. Nichols, and S\&J Farms for allowing us to conduct these experiments in their pistachio orchards; and M. Doster and Y. Luo for advice about data presentation.

\section{LITERATURE CITED}

1. Ahimera, N., Driever, G. F., and Michailides, T. J. 2003. Relationships among propagule numbers of Botryosphaeria dothidea, latent infections, and severity of panicle and shoot blight in pistachio orchards. Plant Dis. 87:846853.

2. Ahimera, N., Gisler, S., Morgan, D. P., and Michailides, T. J. 2004. Effects of single-drop impactions and natural and simulated rains on the dispersal of Botryosphaeria dothidea conidia. Phytopathology 94:1189-1197.

3. Arauz, L. F., and Sutton, T. B. 1989. Temperature and wetness duration requirements for apple infection by Botryosphaeria obtusa. Phytopathology 79:440-444.

4. Driever, G. F., Ntahimpera, N., Michailides, T. J., Morgan, D. P., and Felts, D. 2002. Effect of weather conditions on Botryosphaeria blight of pistachio and development of integrated control approaches (year four). Pages 111-133 in: California Pistachio Industry Production Research Report. California Pistachio Commission, Fresno.

5. Driever, G. F., Ntahimpera, N., Michailides, T. J., Morgan, D. P., Felts, D., and Holtz, B 2001. Effect of weather conditions on Botryosphaeria blight of pistachio and development of integrated control approaches (third year report and three year summary). Pages 133-153 in: California Pistachio Industry Production Research Report. California Pistachio Commission, Fresno.

6. Gillespie, T. J., and Duan, R. X. 1987. A comparison of cylindrical and flat plate sensors for surface wetness duration. Agric. For. Meteorol. 40:61-70.

7. Horsfall, J. G., and Barratt, R. W. 1945. An improved grading system for measuring plant diseases. (Abstr.) Phytopathology 35:655.

8. Lau, Y. F., Gleason, M. L., Zriba, L., Taylor, S. E., and Hinz, P. N. 2000. Effects of coating, deployment angle, and compass orientation on performance of electronic wetness sensors during dew periods. Plant Dis. 84:192-197.

9. Little, T. M. 1985. Analysis of percentage and rating scale data. Hortscience 20:642-644.

10. Little, T. M., and Hills, F. J. 1978. Agricultural Experimentation. John Wiley and Sons, New York.

11. Michailides, T. J., and Morgan, D. P. 1992 Effects of temperature and wetness duration on infection of pistachio by Botryosphaeria dothidea and management of disease by reducing duration of irrigation. Phytopathology 82:13991406.

12. Michailides, T. J., and Morgan, D. P. 2004. Panicle and shoot blight of pistachio: a major threat to the California pistachio industry. APSnet Feature: http://www.apsnet.org/online/ feature/pistachio/

13. Michailides, T. J., Morgan, D. P., and Felts, D. 2000. Detection and significance of symptomless latent infection of Monilinia fructicola in California stone fruit. (Abstr.) Phytopathology 90:S53.

14. Michailides, T. J., Morgan, D. P., Olson, W. H., and Grant, J. A. 1993. Adjusting sprinkler angle reduces spread of disease in pistachio. Calif. Agric. 47:16-20.

15. Michailides, T. J, Teviotdale, B. L., and Weinberger, G. 1999. Botryosphaeria Blight of Pistachio Identification and Control Manual. California Pistachio Commission, Fresno.

16. Mila, A. L., Driever, G. F., Morgan, D. P., and Michailides, T. J. 2005. Effects of latent infection, temperature, precipitation, and irrigation on panicle and shoot blight of pistachio in 
California. Phytopathology 95:926-932.

17. Mila, A. L., and Michailides, T. J. 2006. Use of Bayesian methods to improve prediction of panicle and shoot blight severity of pistachio in California. Phytopathology 96:1142-1147.

18. Mila, A. L., Morgan, D. P., Felts, D., and Michailides, T. J. 2004. Determination of inoculum potential, prediction, and development of integrated control approaches of Botryosphaeria blight of pistachio (2004 Report). Pages 62-71 in: Production Research Report.
California Pistachio Commission, Fresno.

19. Ntahimpera, N., Driever, G. F., Felts, D., Morgan, D. P., and Michailides, T. J. 2002. Dynamics and pattern of infection by Botryosphaeria dothidea on pistachio buds. Plant Dis. 86:282-287.

20. Ntahimpera, N., Driever, G. F., Morgan, D. P., Felts, D., and Michailides, T. J. 2001. Biology, epidemiology, monitoring, and control of Botryosphaeria panicle and shoot blight on pistachio (2001 report). Pages 1-18 in: Cali- fornia Pistachio Industry Production $\mathrm{Re}$ search Report. California Pistachio Commission, Fresno.

21. Ntahimpera, N, Felts, D., Driever, G. F., Morgan, D. P., and Michailides, T. J. 2002. Biology, epidemiology, monitoring and control of Botryosphaeria panicle and shoot blight on pistachio (2002 report). Pages 1-23 in: California Pistachio Industry Production Research Report. California Pistachio Commission, Fresno. 